\title{
*PHRASAL CATEgoRIES IN WORd FORMATION RULES
}

\author{
REINETTE DE VILLIERS
}

\section{Introduction}

This paper deals with one of the properties of the word formation rules of lexicalist morphology. These rules apply within the lexicon to form new words on the basis of already existing words. Roeper and Siegel (1978:202) recently summarized the properties of word formation rules (henceforth WFRs) as follows.

(1) a. WFRs involve no phrasal categories

b. WFR' shift syntactic category

c. WFRs involve no medial variables

d. WFRs have no extrinsic ordering

e. WFRs involve semantic compositionality

f. WFRs permit statement of idiosyncratic information.

It is with the first property (I)a. above that the present paper is concerned. It is obvious why it is important to lexicalists that WFRs should not involve phrasal categories: the number of phrases generated by the syntax is infinite. Consequently these phrases cannot be available as input to WFRs in the form of a finite list in the lexicon. On the other hand, if such phrases had to be generated in the lexicon by means of rules, the lexicon would duplicate the function of the rules responsible for the generation of these phrases in the syntax. Thus Aronoff (1976:47) points out that

(2) "... access to anything other than the base calls for rules of a much more powerful sort than we would prefer to have. We will therefore operate on the assumption that a WFR can be cognizant only of information contained in its own base."

If it could be shown that WFRs do in fact involve phrasai categories, then the very existence of these rules as a distinct type of rule could be questioned. 
The central claim of this paper will be that Afrikaans ${ }^{1}$ ) has verbal compounds which incorporate syntactic phrases as constituents. It will be argued that if these verbal compounds have to be derived by means of WFRs, then WFRs cannot be claimed to have the property (1)a. To develop this argument, we have to consider a currently accepted lexicalist theory of word formation (82), Roeper and Siegel's (1978) theory of verbal compounding in English (\$3) and the relevant Afrikaans verbal compounds (\$4).

\section{A theory of word formation}

Roeper and Siegel (1978:200-204) provide a useful outline of a theory of the lexicon and its word formation component that draws on work by Halle (1973), Jackendoff (1975) and in particular Aronoff (1976). Within the framework of this theory the lexicon contains, among other things, a IEXICAI CORE and a set of WORD FORMATION RULES.

The LEXICAI CORE is a list of words containing two sub-components: the atomic core and the complex core. The atomic core is a list of all those words that have no internal morphological structure. Thus words like church, house and bed will be part of the atomic core. The complex core, on the other hand, is a list of those words that have been created by word formation rules and hence are morphologically structured. Words like housing and bedding are typical examples of words contained in the complex core. Words like possible and happy which appear to have morphological structure but which are not compositional in meaning, are listed in the atomic core ${ }^{2)}$.

The WORD FORMATION RULES (WFRs) are rules which operate completely within the lexicon. Aronoff $(1976: 46)$ states that although WFRs make reference to syntactic, semantic and phonological properties of words, they are totally separate from the other rules of a gramar. Words from the lexical core serve as input to WFRs which create new words on the basis of these core words. Thus there is a WFR which creates words like housing and bedding by adding -ing to the already existing words house and bed. The output of WFRs may either be inserted into syntactic structures via lexical insertion rules or they may be inserted into the complex core 
De Villiers 41

where they are stored in a long-term memory. Words formed by WFRs and stored in the complex core may serve as input to other WFRs (cf. (3) below).

The properties which WFRs are claimed to have, have already been listed as (I) above.

In addition to WFRs the lexicon contains a number of other devices, including allomorphy adjustment rules and stress assignment rules, the nature and function of which are irrelevant to the aim of this paper.

To summarize their observations about the structure of the lexicon, Roeper and Siegel (1978:204) present a flow chart developed by Keyser and Carlson.

(3)

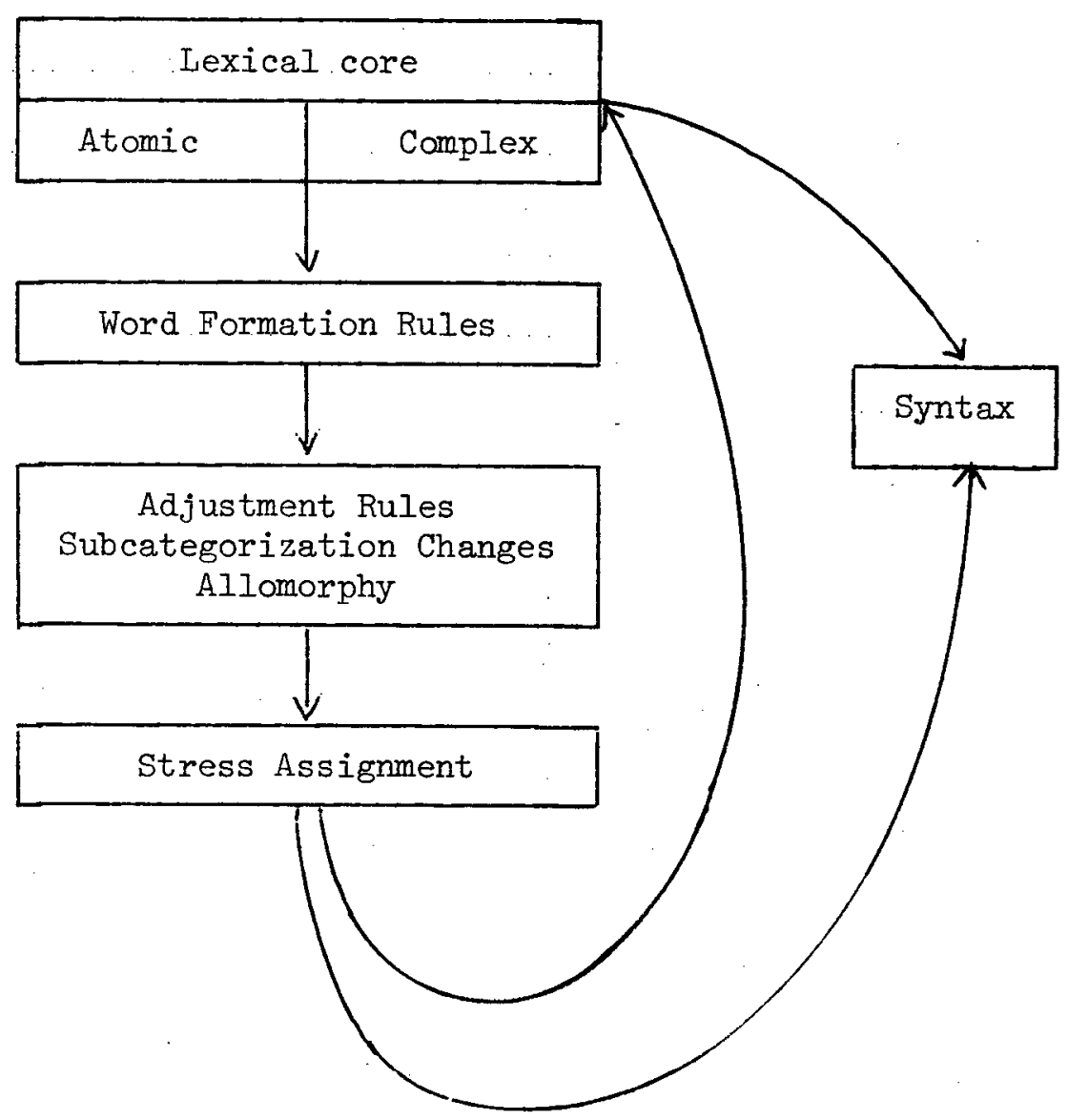

From the flow chart (3) it is clear that the output of these rules which apply in the lexicon may either directly enter the syntax or be inserted into the lexical core where it will be stored in a long-term memory. This allows for recursion in word formation because complex forms can now 
serve as input to further WFRs. Note that there are two points of entry into the syntax --- one from the core and the other directly from the WFRs. Thus certain newly formed words are not listed in the core, but are analysed during sentence processing. The following remarks by Roeper and Siegel (1978:204) provide further clarification of this point.

(4) "Words with particularly frequent affixes could not all be listed in the core. For instance, the lly adverbs are so numerous that it would be inefficient to remember each one."

It is not at all clear which formal principles may serve as a basis for the distinction between those WFRs of which the output should be inserted into the lexical core and those WFRs of which the output should be inserted into syntactic base structures.

\section{A theory of verbal compounding}

Within the framework of the lexicalist theory outlined in B2, Roeper and Siegel (1978) propose a theory of verbal compouncing for English. Amongst other rules they propose a transformation --- the Compound Rule --which applies within the lexicon to form verbal compounds in English.

\subsection{Verbal compounds and root compounds}

Roeper and Siegel (1978:206) distinguish between VERBAL COMPOUNDS --such as oven + clean + er, hard + work + ing, fast + act + ing, etc. --- and ROOT COMPOUNDS --- such as bed + bug, window + shop, baby + sit, etc. This distinction is based on the fact that verbal compounds (i) are marked by the verbal affixes -er, -ing or -ed; (ii) have verbs as base words and (iii) are predictable and compositional with regard to meaning. Root compounds, by contrast, (i) need not show any morphological marking, (ii) may combine any syntactic categories and (iii) may be unpredictable in meaning.

The WFRs proposed by Roeper and Siegel (1978) have to account for the formation of verbal compounds. Root compounds, on the other hand, are listed in the atomic core of the lexicon because they are "as unpredict- 
able as ordinary words" $(1978: 206)^{3)}$.

\subsection{The First Sister Principle}

The central principle in Roeper and Siegel's account of verbal compounds in English (1978:208) is the First Sister (FS) Principle.

\section{(5) First Sister (FS) Principle}

All verbal compounds are formed by incorporation of a word in first sister position of the verb.

Thus, a word may be incorporated in a verbal compound only if it can appear in the FS position of the verb -- that is in the position immediately to the right of the verb. The fact that *huge going does not exist, therefore, follows from the fact that huge may not appear in the FS position of the verb go. For instance, (6) does not exist.

$$
\begin{array}{cc}
\text { V. } & \text { FS } \\
\text { * go huge }
\end{array}
$$

The existence of good-looker, by contrast, is explained by the fact that good can appear in the FS position of the verb look, as in (7).

$$
\begin{array}{cc}
\text { V } & \text { FS } \\
\text { look } & \text { good } \\
\hline
\end{array}
$$

The FS principle is expressed in the Compound Rule which Roeper and Siegel (1978:209) propose for the formation of verbal compounds. This rule, presented as (8) below, moves a word from the FS position to the left of a verb.

Compound Rule

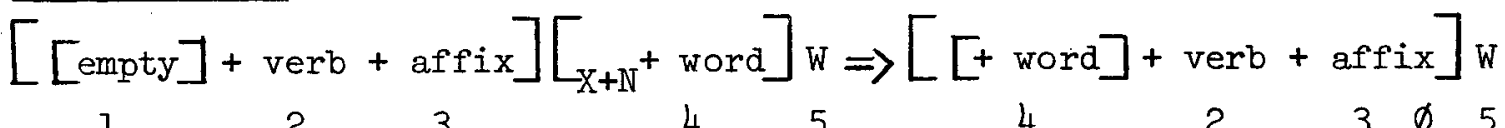
1 23 45

where $W$ ranges over subcategorization frames and $X+N$ stands for lexical categories $N, A, A d v .{ }^{4}$ )

The operation of the Compound Rule can be illustrated by the example in (9). 
De Villiers 44

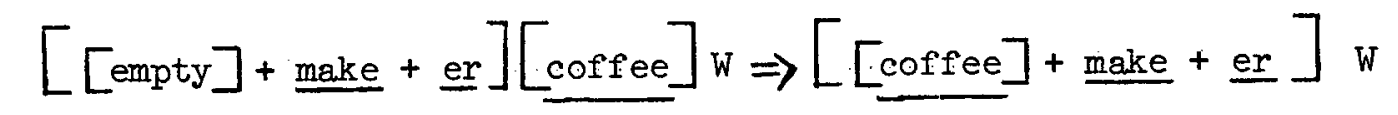

\subsection{Other rules involved in verbal compounding}

In addition to the Compound Rule (8) Roeper and Siegel (1978) propose various other rules which, they claim, operate in the formation of verbal compounds.

Because of variations among the verbal affixes, =er, -ing and -ed, Roeper and Siegel (1978:210) propose three different AFF'IXATION RULES. The functioning of these rules may be illustrated schematically as follows.

$$
\begin{aligned}
& \text { verb } W \Rightarrow[\text { empty }]+\text { verb + affix } W \\
& \text { where } W \text { ranges over subcategorization frames }
\end{aligned}
$$

Verbs with their subcategorization frames taken from the lexical core form the input to these rules. The affixation rules provide empty frames to be attached to the left of verbs, and affixes to be attached to the right of verbs. An example of the functioning of affixation is presented in (11).

(II) make $W \Rightarrow[$ empty $]+\underline{\text { make }}+\underline{\text { er }} \mathrm{W}$.

The SUBCATEGORIZATION INSERTION RULE proposed by Roeper and Siegel (1978: 211) functions in a way similar to lexical insertion rules. It selects a lexical item from the lexical core and inserts it into a subcategorization frame to the right of a verb. This rule must insert a lexical item into every obligatory subcategorization frame and may or may not insert such an item into an optional subcategorization frame. 5) In accordance with the restriction on lexical rules, expressed in (1)a. above, this mule may not insert phrases into subcategorization frames. Therefore the phrase brackets are eliminated from the subcategorization frames and cannot be expanded. NP becomes $N$, Adj P becomes Adj. and Adv P becomes Adv. In terms of $\bar{x}$-notation, the Subcategorization Insertion Rule can be presented as (12). 


$$
\frac{\text { Subcategorization Insertion }}{[\overline{\bar{x}} \text { empty }] \Rightarrow\left[{ }_{\mathrm{X}}+\text { word }\right]}
$$

The operation of the rule (12) is illustrated in (13).

$$
\left[\begin{array}{ll}
\overline{\bar{x}} & \text { empty }
\end{array}\right] \Rightarrow\left[\begin{array}{l}
\text { coffee } \\
\text { cof }
\end{array}\right]
$$

Any number of empty optional subcategorization frames may occur between the filled frame and the verb. In such cases the words inserted by the rule (12) will not be in the FS position of the verb. To overcome this problem, Roeper and Siegel (1978:212) propose an adjustment rule --the VARIABLE DELETION RULE -- to delete all the empty phrases between the verb and the word inserted by rule (12). Empty subcategorization frames deleted by this rule will not be available for lexical insertion in syntax. 6) The general form of the Variable Deletion Rule is presented in (14).

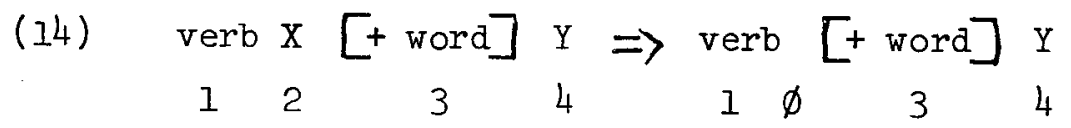

where $X$ and $Y$ range over empty subcategorization frames

After the application of the Rules of Affixation, the Subcategorization Insertion Rule and the Variable Deletion Rule, the Compound Rule (8) applies. This rule removes a word from the FS position --- where it appears after application of the Subcategorization Rule --- and inserts it into an empty frame to the left of a verb, the empty frame being supplied by the Rules of Affixation.

\subsection{The Compound Rule and English verbal compounds}

Roeper and Siegel (1978:213-217) argue that the properties of the Compound Rule (8) are consistent with the formal properties of WFRs (cf. (1) above) and that this rule must therefore be regarded as a WFR.

In their discussion (1978:213-214) of the property (1)a., i.e. the restriction that WFRs may not involve phrases, they state that the Subcategoriza- 
De Villiers 46

tion Insertion Rule (12) selects a word from the lexical core and inserts it into a subcategorization frame as a noun, adjective or adverb. It follows that words and not phrases form the input to the Compound Rule (8). Thus good-looker in (15)a., which is formed on the basis of the adjective good, is acceptable. By contrast, *very good-looker in (15)b., which is formed on the basis of an adjectival phrase, very good, is not acceptable.

$$
\begin{aligned}
& \text { a. look }[\text { good }]_{\mathrm{A}} \Rightarrow \text { good-looker } \\
& \text { b. } \quad \text { look }[\text { very good }]_{\mathrm{AP}} \Rightarrow \text { *very good-looker }
\end{aligned}
$$

\subsection{Diagnostics for verbal compounds}

In $\$ 4$ Roeper and Siegel (1978:217-225) discuss several apparent verbal compounds which seem to be counter-examples for their FS principle (cf. (5) in 83.2 above). They argue that these examples are not in fact verbal compounds but that they should be analysed as either (i) phrase structure generated sequences or (ii) derivations with root compounds as bases. In this discussion they develop a number of diagnostics for verbal compounds. These diagnostics are presented in the form of the questions in (16).

(16) a. Does it have an affix (-er, -ing, -ed)? (boatmaker)

b. Does it have a non-independent verb form? (church-goer) \& goer)

c. Does it fail to allow the Rythm Rule ? (Chinése-lover)

d. Does it take -re internally (story-retelling)

e. Does it have no related compound verb (time-consuming; time-consumer)

f. Does the compound have a generic reading?

g. Does the compound violate selectional restrictions if analysed as a relative clause?

If the answer to the question (a) and any one of the remaining questions, is affirmative, then the form in question is a verbal compound that will obey the FS principle. 
4. The formation of verbal compounds in Afrikaans

Afrikaans verbal compounds appear to be formed in accordance with the theory of verbal compounding proposed by Roeper and Siegel (1978) for English. Thus, the example koffiedrinker ("coffee drinker") can be analyzed as follows.

The verb drink ("drink") and its subcategorization frames form the input to an affixation rule (cf. (10) above) which attaches an empty frame to the left of the verb drink and the affix -er to the right of it. The Subcategorization Insertion Rule ( $\mathrm{cf}$. (12) above) is responsible for the insertion of a word, the noun koffie ("coffee") into the relevant subcategorization frame of the verb, drink. Any optional subcategorization frames which might appear between the verb drink and the noun, koffie will be deleted by the Variable Deletion Rule (cf. (14) above). The Compound Rule (cf. ( 8 ) above) moves the noun koffie ("coffee") and inserts it into the empty frame --- provided by the affixation rule --- to the left of the verb drink ("drink").

Although Afrikaans verbal compounds are formed in accordance with the theory of verbal compounding outlined in 33, Afrikaans has a class of complex forms which seem to be problematic within the lexicalist theory outlined in 82 . These complex forms have the properties of verbal compounds and obey the FS principle but they include phrases. Because WFRs may not involve phrases, one would attempt to avoid analysing these forms as verbal compounds. However, it will be argued that these complex forms cannot be analysed as anything but verbal compounds and that they appear, therefore, to be counter-examples to the claim that WFRs do not involve phrasal categories.

The complex forms under consideration belong to different classes in terms of the phrases which they incorporate and will be discussed separately .

\section{I Adverbial phrases incorporated in verbal compounds}

A first set of examples which will be considered comprises a class of 
complex forms containing an adverbial phrase of the type adverb + adverb.

a. baie-laat-slaper

very late sleeper

a person who usually sleeps very late

b. baie-lekker-lagger very heartily laugher

a person who usually laughs very heartily

c. besonder-hard-prater extraordinarily loud talker

a person who usually talks extraordinarily loud

d. besonder-klein-skrywer extraordinarily small writer a person who usually writes extraordinarily small

e. baie-laat-kommer

a person who usually comes very late

Each of the examples in (17) above ( $i$ ) has a verbal affix, ( $i i)$ has a verb as base word, ( $i i i$ ) is compositional in meaning and ( $i v$ ) has a generic reading. Furthermore, the phrases included in these forms may all occur in the FS position of the accompanying verb as can be seen in (18).

$$
\mathrm{V}
$$

FS
a. slaap baie laat
sleep very late
b. lag baie lekker
laugh very heartily
c. praat besonder hard
talk extraordinarily loud
d. skryf besonder klein
write extraordinarily small




$$
\begin{array}{cc}
\text { V } & \text { FS } \\
\text { e. } \quad \frac{\text { kom }}{\text { come }} & \frac{\text { baie laat }}{\text { very late }}
\end{array}
$$

Although the examples in (17) have the properties of verbal compounds, they all include phrases. If these forms are analysed as verbal compounds, they constitute counter-examples to the claim that WFRs may not involve phrases (cf. (1)a. above). So let us consider alternative analyses for these examples.

A first alternative would be to exclude the complex forms in (17) as true counter-examples on the same grounds as those on which Roeper and Siegel (1978:214) exclude (19) below as a true counter-example.

\section{(19) very good lover}

Roeper and Siegel argue that a very good lover is not someone who loves very good, but rather a lover who is very good. They claim that (19) is formed by separate insertion of the adverb very, the adjective good and the noun lover into phrase structure. Therefore (19) is analysed, not as a verbal compound, but as a "phrase structure generated adverb-adjective-noun sequence (sic!)". Roeper and Siegel (1978:218) formulate the following criterion for deciding whether or not a particular form is a sequence generated by lexical insertion into phrase structure.

(20) "In a PS-generated sequence each lexical item must have a separate representation in the lexical core."

If a lexical item in a putative phrase structure generated sequence does not exist independently, it follows that the considered example cannot be analysed as a phrase structure generated sequence. However, this does not mean that verbal compounds can never include independently existing words (cf. Roeper and Siegel (1978:226)).

The independent existence of each lexical item is not the only criterion for deciding whether a particular example is to be analysed as a phrase structure generated sequence. Roeper and Siegel (1978:223) argue that the examples in (2I) below cannot be analysed as PS-generated sequences, 
not only on account of the fact that the putative nouns do not exist independently, but also because the putative adjectives have adverbial readings and must be analysed as adverbs. They analyse the examples in (2l) as verbal compounds incorporating adverbs.

(21) a. early riser

b. slow burner

c. late comer

d. late bloomer

e. late sleeper

If the Afrikaans examples in (17) were regarded as PS-generated sequences consisting of an adverb, an adjective and a noun, they would have to be analysed as in (22).

\begin{tabular}{|c|c|c|c|}
\hline & ADVERB & DJECTIVE & NOUN \\
\hline \multirow[t]{2}{*}{ a. } & baie & laat & slaper \\
\hline & very & late & sleeper \\
\hline \multirow[t]{2}{*}{$\mathrm{b}$. } & baie & lekker & lagger \\
\hline & very & hearty & laugher \\
\hline \multirow[t]{2}{*}{ c. } & besonder & hard & prater \\
\hline & extraordinarily & loud & talker \\
\hline \multirow[t]{2}{*}{ d. } & besonder & klein & skrywer \\
\hline & extraordinarily & small & writer \\
\hline \multirow[t]{2}{*}{ e. } & baie & laat & kommer \\
\hline & very & late & comer \\
\hline
\end{tabular}

If the analysis (22) for the examples in (17) were to be accepted it would have to be shown (i) that the putative nouns in (22) exist as independent nouns in Afrikaans and (ii) that the putative adjectives in (22) are indeed adjectives.

With regard to the independent existence of the putative nouns in (22), let us consider the sentences (23) below. Following Roeper and Siegel 
(1978) possible but non-existing forms are marked with a $\underline{\&}$ while dubious cases will be marked with a question mark.

(23) ? $\frac{\text { Hy is 'n slaper }}{\text { he is a sleeper }}$
b. \& $\frac{\text { Hy is 'n lagger }}{\text { he is a laugher }}$
c. ? $\frac{\text { Hy is 'n prater }}{\text { he is a talker }}$
d. Hy is 'n skrywer
he is a writer
\& Hy is 'n kommer
he is a comer

The complex forms in (22)b. and e. do not do not include independently existing nouns and can therefore, not be analysed as phrase structure generated sequences ( $\mathrm{cf}$. (20) above).

In contrast, the form in (22)d. includes an independently existing noun and the possibility exists that the complex form in (22)d. can be analysed as a phrase structure generated sequence. To determine whether such an analysis holds, it must be determined whether the putative adjective klein ("small") is indeed an adjective.

In the case of the complex forms in (22)a. and c. it is questionable whether or not the putative nouns could be considered as having independent existence. As in the case of the form in (22)d. it cannot be argued on this ground only that the analyses in (22)a. and c. are to be rejected. We will thus turn to a second consideration, namely the question as to whether or not the putative adjectives in (22) are indeed to be analysed as adjectives.

It will be argued that in the complex forms in (22) the putative adjective in each case is not an adjective but an adverb. The putative adjectives 
all have adverbial readings. Laat ("late") in (22)a., for instance, does not relate to the putative noun ?slaper ("sleeper") but to the verb slaap ("sleep"). Thus, baie-laat-slaper must be paraphrased as "a person who sleeps very late" and not as "a sleeper who is very late". In the same way the putative adjective in every other complex form in (22) relates to the verb incorporated in the putative noun and not to the noun itself.

Further evidence that the putative adjective hard ("loud") in (22)c. cannot be analysed as an adjective is the fact that it lacks a typical morphological property of adjectives. In Afrikaans certain adjectives have the suffix $=e$ when used attributively. Hard in fact has this property when it is used conventionally as an attributive adjective. Thus compare the acceptable a.-form (harde) with the unacceptable b.form (hard).

$$
\begin{aligned}
& \text { a. Die harde geluid } \\
& \text { The loud noise } \\
& \text { b. } \quad \text { Die hard geluid }
\end{aligned}
$$

Thus the analysis (22) in which the examples in (17) are analysed as PSgenerated sequences, each consisting of an adverb, an adjective and a noun, cannot be upheld.

A second alternative would be to analyse the Afrikaans examples in (17) as sequences into which an adjective and a noun have been inserted separately. On this analysis the noun would, in each case, be a verbal compound incorporating an adverb as its first constituent as in (25).

ADJECTIVE

a.

b.

c.

$$
\frac{\text { baie }}{\text { very }}
$$

$\underline{\text { baie }}$ very

besonder extraordinarily
VERBAL COMPOUND $=$ NOUN

laatslaper

late sleeper

lekkerlagger heartily laugher

hardprater loud talker 
ADJECTIVE

d.

e. baie
VERBAL COMPOUND $=$ NOUN

kleinskrywer

small writer

laatkommer

late comer

The analysis (25) of the examples in (17) however, cannot be accepted. There is no way in which it can be argued that the adverbs analysed as putative adjectives in (25) are indeed adjectives. In each case the putative adjective modifies the adverb incorporated in the verbal compound and not the noun formed by verbal compounding. Thus, baie lekkerlagger should be paraphrased as "a person who laughs very heartily" and not as "a heartily laugher who is very".

With regard to the complex forms in (25)c. and d. further evidence that the putative adjectives cannot be analysed as adjectives exists. As in the case of the putative adjective hard in (2)c., besonder has the suffix -e when used as an attributive adjective. Thus compare the acceptable a.-form (besondere) with the unacceptable b.-form (besonder) in (26) below.

(26) a. Die besondere boek

The extraordinary book

\section{b. *Die besonder boek}

It has been shown that the analyses (22) and (25) for the complex forms in (17) cannot be accepted. Thus the forms in (17) cannot be regarded as PS-generated sequences. But let us consider yet another alternative analysis for these complex forms.

Let us assume that the Afrikaans forms in (17) are formed by WFRs which add a verbal affix to a root-compound verb, which is taken from the atomic core (cf. footnote 2). In such a case the examples in (17) can be analysed as in (27). 

a. baie-laat-slaap
-er.

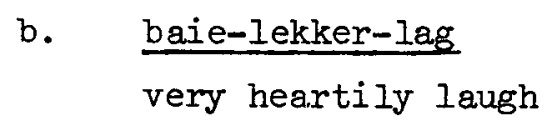

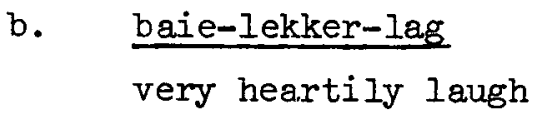
er
-er
er

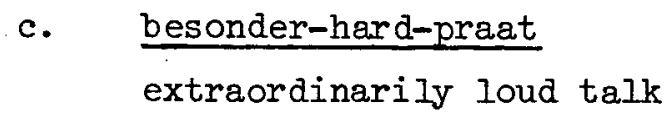
-er
er

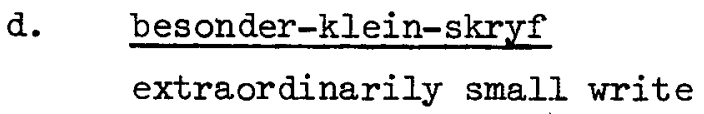
-er
er
e. baie-laat-kom
very late come
-er
er

The analysis (27), however, must be rejected. The putative root-compound verbs in (27) cannot be analysed as verbs since they lack typical morphological and syntactic properties of Afrikaans verbs. Compare, for example, the acceptable (i)-forms to the unacceptable (ii)-forms in (28) and (29).

\section{PRESEITT TEINSE}

a. (i) Hy slaap.

He sleeps

(ii) *Hy baie laat slaap

b. (i) Hy lag.

He laughs

(ii) *Hy baie lekker Iag

c. (i) Hy praat.

He talks

(ii) *Hy besonder hard praat

d. (i) Hy skryf.

He writes

(ii) *Hy besonder klein skryf 
PRESENT TENSE

e. (i) Hy kom.

He comes

(ii) * Hy baie laat kom

(29)

\section{PAST TENSE}

a. (i) Hy het geslaap.

He slept

(ii) *Hy het gebaie laat slaap

b. (i) Hy het gelag.

Hy laughed

(ii) *Hy het gebaie lekker lag

c. (i) Hy het gepraat.

He talked

(ii) * Hy het gebesonder hard praat

d. (i) Hy het geskryf.

He wrote

(ii) *Hy het gebesonder klein skryf

e. (i) Hy het gekom.

He came

(ii) * Hy het gebaie laat kom

It is clear that the putative root-compound verbs in (27) cannot be analysed as verbs. Thus the analysis (27) cannot be accepted.

It is therefore difficult to avoid the conclusion that the only remaining possibility is to analyse the examples presented in (17) as verbal compounds?) If the examples in (17) are verbal compounds, it follows that at least those WFRs responsible for the forming of the expressions in (17) involve phrasal categories.

Further examples of complex forms in Afrikaans containing phrases of the type adverb + adverb, which I believe cannot be analysed as anything but 
verbal compounds, are presented below.

\author{
(30) a. baie-hard-werkery \\ very hard working \\ the act of working very hard \\ b. baie-vinnig-drawwery \\ very fast jogging \\ the act of jogging very fast \\ c. baie-mooi-lykery \\ very pretty looking \\ the act of looking very pretty \\ a. besonder-lusteloos-voelery \\ extraordinarily-listless-feeling \\ the act of feeling extraordinarily listless \\ e. vreeslik-vinnig-ryery \\ terribly-fast-driving \\ the act of driving terribly fast
}

\title{
4.2 Postpositions incorporated in verbal compounds
}

Roeper and Siegel (1978:242) show that some English verbal compounds appear to violate their FS principle as they incorporate words which may only appear in the FS position of the verb when preceded by a preposition. Thus church in the verbal compound church-goer can only appear in the FS position of the verb go when it is preceded by the preposition to.

$\begin{array}{ccl} & \text { V } & \text { FS } \\ \text { a. } & \text { *go } & \text { church } \\ \text { b. } & \text { go } & \text { to church }\end{array}$

To account for this fact, they (1978:242) reformulate their Subcategorization Insertion Rule. This rule can now insert a preposition immediately 
De Villiers 57

to the left of the word which it inserts in the FS position of a verb. The question for Roeper and Siegel, now, is how to explain the fact that such prepositions never occur in English verbal compounds. They argue that this question does not pose a real problem. Their Variable Deletion Rule which was formulated to delete all empty frames which occur between the verb and the frame filled by Subcategorization Insertion, will now delete "everything that falls between' verb and [+ word]" (1978: 242). Thus the preposition inserted in front of a word in the FS position of a verb is deleted before the Compound Rule applies. In this way the Compound Rule does not involve a phrase but a single word (cf. (I)a).

One of the Afrikaans expressions corresponding to go to church contains the postposition toe ("to").

\begin{tabular}{|c|c|}
\hline V & FS \\
\hline gaan & kerk toe \\
\hline go & chureh to \\
\hline go & to church \\
\hline
\end{tabular}

On the basis of this expression both the following compounds may be formed.

(33) $\begin{aligned} & \frac{\text { kerkganger }}{\text { church goer }} \\ & \text { church-goer }\end{aligned}$
b.
$\frac{\text { kerk-toe-ganer }}{\text { church to goer }}$
church-goer

The complex form in (33)b. apparently incorporates a phrase consisting of a noun and a postposition. The question of course, is whether or not the complex form kerk-toe-ganer has to be analysed as a verbal compound. It will be argued that this form can be analysed neither as a phrase structure generated sequence nor as a complex form formed by the adding of a verbal affix to a root-compound verb. The only plausible analysis of the complex form in (33)b., it will be argued, assigns it the status of a verbal compound. 
A first analysis in terms of which the complex form in (33)b. is not treated as a verbal compound, assigns it the status of a phrase structure generated sequence into which independently existing lexical items have been inserted.

\begin{tabular}{|c|c|c|}
\hline NOUN & POSTPOSITION & NOUN \\
\hline kerk & toe & ganer \\
\hline church & to & goer \\
\hline
\end{tabular}

The putative noun $\underline{\&}$ ganer ("goer"), however, does not exist as an independent noun of Afrikaans. In accordance with the criterion (20) above, the analysis (34) in which the form kerk-toe-ganer ("church-goer") is analysed as a phrase structure generated sequence, cannot be accepted.

Further evidence that the analysis (34) does not hold follows from the fact that the phrase kerk toe ("to church") must be analysed as an adverbial phrase. The phrase under consideration does not relate to the putative noun \& ganer ("goer") but rather to the verb gaan ("go"). In (35) it may be seen that this phrase does not function adjectivally in sequences similar to the putative phrase structure generated sequence in (34).

$$
\begin{aligned}
& \text { NOUN POSTPOSITION NOUN } \\
& \text { a. *kerk toe man } \\
& \text { b. *kerk toe skoene }
\end{aligned}
$$

A second alternative would be to assign the form (33)b. the status of a complex form in which a verbal affix is attached to a root-compound verb.

$\begin{array}{lc}\text { ROOT-COMPOUN VERB } & \text { VERBAL AFFIX } \\ \text { kerk-toe-gaan } & \text { er } \\ \text { church to go } & \text { er }\end{array}$

The analysis (36) cannot be accepted. The putative root-compound verb kerk-toe-gaan cannot be analysed as a verb. It exhibits neither the typical syntactic not the typical morphological properties of Afrikaans verbs. 

(37) a. (i) $\frac{E k \text { gaan }}{I \text { go }}$
(ii) $\frac{\text { *Ek kerk-toe-gaan }}{\text { I church to go }}$
b. (i) Ek het gegaan
I have gone
(ii) *Ek het ge-kerktoe-gaan
I have church to went

From (37) it is clear that kerk toe gaan ("church to go") does not function as a single verb unit, neither when used in the present tense (cf. (37)a.) nor when used in the past tense (cf. (37)b.).

The alternative analyses for the complex form kerk toe ganer ("church-goer") cannot be accepted. It follows that this form is a verbal compound which is a counter-example to the claim (1)a. above because it incorporates a phrase as first constituent.

Other complex forms which have to be analysed as verbal compounds but which contain the postposition toe ("to") are presented in (38).

(38) a. werk-toe-stapper work to walker

a person who usually walks to work

b. huis-toe-verlanger home to longer

a person who often longs for home

c. Kaap-toe-beller

Cape to phoner

a person who often phones to the Cape

d. wildtuin-toe-ganery

game reserve to going

the act of going to the game reserve 
e. Kanada-toe-emigreerdery

Canada to emigrating

the act of emigrating to Canada

Let us consider the role of other postpositions in Afrikaans verbal compounds.

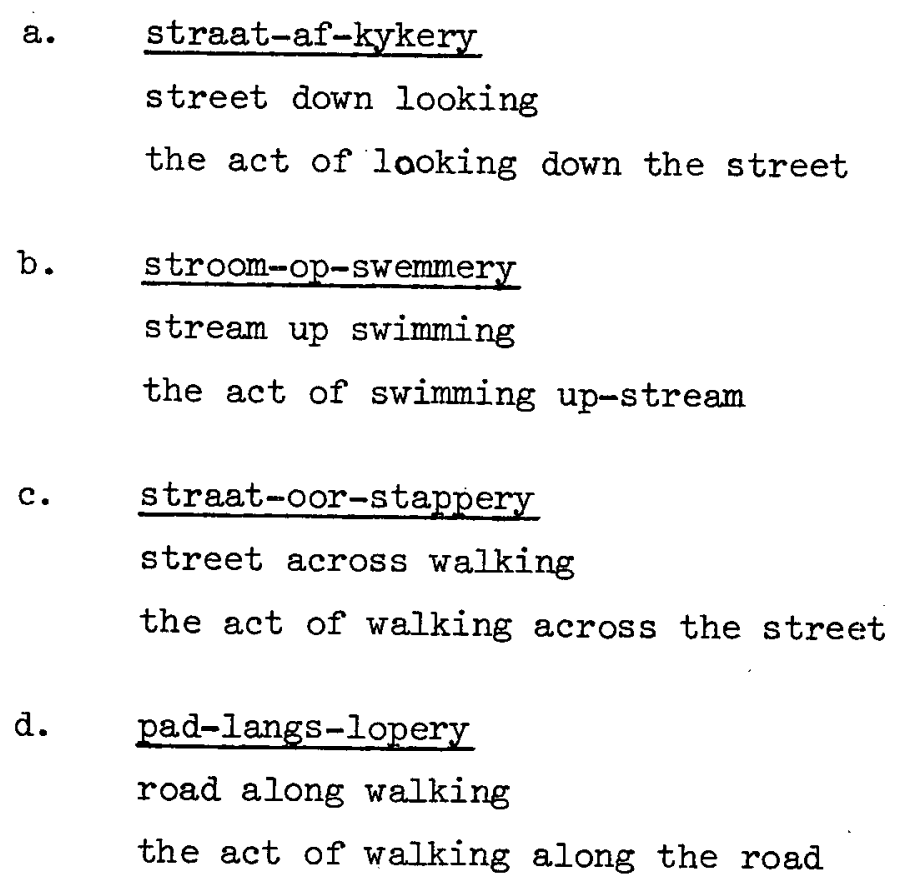

All the complex forms in (39) have the properties of verbal compounds and obey the FS principle. Although they have phrases as first constituents, they cannot be analysed as anything but verbal compounds. Thus the complex forms in (39) together with those in (38) and (33) b. constitute counterexamples to the claim that WFRs do not involve phrases.

\subsection{Prepositions incorporated in verbal compounds}

We turn next to complex forms in Afrikaans which appear to be verbal compounds but which incorporate a prepositional phrase as first constituent. Consider the forms in (40) which incorporate locative prepositional phrases.

(40) a. in-die-bed-lêer in the bed lier

a person who habitually lies in bed 
b. agter-die-muur-roker

behind the wall smoker

a person who usually smokes behind the wall

c. op-die-stoep-sitter

on the stoep sitter

a person who usually sits on the stoep

Each of the complex forms in (40) has the properties of verbal compounds and obey the FS principle as is illustrated in (4I).

(41)
$\mathrm{V}$
FS
a. $\frac{1 \hat{e}}{\text { lie }}$
in die bed
in the bed
b. rook
agter die muur
smoke
behind the wall
c. sit
op die stoep
on the stoep

If the complex forms presented in (40) have to be analysed as verbal compounds, they will be counter-examples to the claim (I)a. that WFRs do not involve phrases. The question now arises whether or not there is a plausible analysis of these forms which does not assign them the status of verbal compounds.

It will be argued that the forms in (40) cannot be analysed as phrase structure generated sequences in which independently existing words have been inserted separately. An analysis along these lines is presented in (42).

$\begin{array}{ll}\text { a. LOCATIVE PHRASE } & \text { NOUN } \\ \frac{\text { in die bed }}{\text { in the bed }} & \frac{\text { leer }}{\text { lier }} \\ \text { b. } & \text { agter die muur } \\ \text { behind the wall } & \text { soker } \\ \text { c. op die stoep } & \text { sitter } \\ \text { on the stoep } & \text { sitter }\end{array}$


The analysis (42), however, cannot be accepted. Under such an analysis one would expect the putative locative phrases to modify the putative nouns. Thus a. would be a \& lier who is in bed, b. a smoker who is behind the wall, and c. a ? sitter who is on the stoep. In fact, however, the smoker in b. for instance, could be in the dining room or anywhere else at the moment of speaking, but his smoking is habitually done behind the wall. Thus it seems that the locative phrases in (42) do not modify the putative nouns but rather the verbs 1 e ("lie"), rook ("smoke") and sit ("sit"), and thus seem not to be adjectival phrases. If the locative phrases in (42) are analysed as adjectival phrases, it follows that these phrases can freely combine with nominals including those which have no internal morphological structure. This however, is not the case.

(43) (i) $\frac{\text { Jan is 'n groot man }}{\text { John is a big man }}$
(ii) *Jan is 'n in die bed man
John is a in the bed man
(ii) *Ek het 'n agter die muur sigaret
(i) have a behind the wall cigarette
(i) Jan is 'n lui man
(ii) *Jan is 'n op die stoep man
John is a lazy man

Furthermore, if the analysis (42) were to be accepted, it would follow that each of the lexical items is an independently existing word of Afrikaans. (cf. (20) above). The cases (42)a. and c., however, both contain a complex nominal element which does not exist as an independent noun of Afrikaans In this respect, therefore, the analysis (42) holds for neither of these two forms.

(44) a. \& lêer
lier
b. \& sitter


In terms of a second alternative analysis the complex forms in (40) could be claimed to be formed by adding a verbal affix to a root-compound verb.

(45)

$\begin{array}{lr}\text { ROOT-COMPOUND VERB } & \text { VERBAI } \\ \text { in die bed lie } & \frac{\text { er }}{\text { er }} \\ \text { b. } \frac{\text { agter die muur rook }}{\text { behind the wall smoke }} & \text { er } \\ \text { c. op die stoep sit } & \text { er } \\ \text { on the stoep sit } & \text { er }\end{array}$

The analysis (45) must be rejected. The putative root-compound verbs cannot be analysed as verbs for they lack the typical syntactic and morphological properties of Afrikaans verbs. Compare, for instance, (46) and (47).

$$
\begin{aligned}
& \text { a. (i) } \frac{\frac{E k \text { lê }}{\text { I lie }}}{\frac{* E k \text { in die bed lê }}{\text { I in the bed lie }}} \\
& \text { b. (i) } \frac{\text { Ek rook }}{\text { I smoke }} \\
& \text { (ii) *Ek agter die muur rook } \\
& \text { (i) } \frac{\text { Ek sit sind the wall smoke }}{\text { I sit }} \\
& \text { (ii) *Ek op die stoep sit } \\
& \text { I on the stoep sit }
\end{aligned}
$$

The unacceptable (ii)-forms in (46) illustrate that the putative root-compound verbs in (45) do not function as a single verbal unit in present tense sentences.

(47) a. (i) Ek het gelê

I lay

(ii) *Ek het ge-in die bed le

I have in the bed lain 
b. (i) Ek het gerook

I smoked

(ii) *Ek het ge-agter die muur rook

I have behind the wall smoked

c. (i) Ek het gesit

I sat

(ii) *Ek het ge-op die stoep sit

I have on the stoep sat

The putative root-compound verbs in (45) do not function as a verbal unit in past tense sentences as is illustrated in the unacceptable (ii)-forms in (47).

It seems that the complex forms in (40) must be analysed as verbal compounds and are thus counter-examples to the claim that WFRs do not involve phrases.

Apart from locative prepositional phrases, other prepositions can also be included in Afrikaans verbal compounds.

(48) a. met-mekaar-stryery

with each other arguing

the act of arguing with each other

b. oor-mekaar-vallery

over each other falling

the act of falling over each other

c. tussen-leiers-kiesery

between leaders choosing

the act of choosing between leaders 
4.4. Other phrases incorporated in verbal compounds

In the preceding sections several counter-examples to the claim that WFRs do not involve phrasal categories were dealt with. Afrikaans has additional verbal compounds which are counter-examples to this claim (1)a. Instead of analysing these forms in detail, I simply list them below. Interestingly some of these forms include more than one phrase.

(49)

$\underline{\text { Adverb }+P P \text { incorporated }}$

$\underline{A d v} \quad \underline{P P} \quad \underline{\text { affix }}$

a. laat-in-die-bed-kommery

late in the bed coming

the getting to bed late

$\underline{A d v} \quad \underline{P P} \quad \underline{V} \underline{a f f i x}$

b. voor-in-die-kerk-sitter

in front in the church sitter

a person who usually sits in the front when in church

(50)

$\underline{N}+\mathrm{PP}$ incorporated

$$
\text { N } \quad \underline{\text { PP }} \quad \underline{\text { affix }}
$$

a. boek-in-die-bed-lesende book in the bed reading adjective used to describe someone who reads a book in bed

$$
\text { N } \quad \underline{P P} \quad \underline{\text { affix }}
$$

b. stoele-op-die-tafels-pakkery

chairs on the tables packing

the packing of chairs on tables

(51)

$\underline{\mathrm{PP}+\mathrm{PP} \text { incorporated }}$

$\underline{P P} \quad \underline{P P} \quad \underline{V} \underline{a f i x}$

a. met-die-hand-in-die-sak-stanery

with the hand in the pocket standing

the standing with one's hand in one's pocket 
PP $\quad \underline{\text { PP }} \quad \underline{\mathrm{affix}}$

b. met-die-handsak-onder-die-arm-lopery.

with the handbag under the arm walking

the walking with a handbag under one's arm

NP incorporated

NP $\quad$ V affix

a. groente-en-vrugte-liefhebber

vegetables and fruit lover

a. person who loves to eat vegetables and fruit

NP $\quad$ V affix

b. vroue-en-kinder-hater

women and children hater

a person who hates women and children

\section{A few concluding remarks}

Within the lexicalist theory of morphology outlined in $\$ 2$, WFRs constitute a distinct type of rule which functions within the lexicon and which is totally separate from the other rules of a gramar. One of the properties that WFRs are claimed to have is that they do not involve phrases. Afrikaans has numerous examples of complex forms which have to be analysed as verbal compounds and which are formed by means of a WFR such as the Compound Rule (8). These verbal compounds involve a phrase as first constituent and thus constitute counter-examples to the claim that WFR do not involve phrases.

If WFRs do involve phrases, these phrases will either have to be listed in the lexical core or they will have to be generated in the lexicon by means of rules. The first alternative is not acceptable because the number of phrases is infinite and therefore cannot be stored in a finite list. On the other hand, the second alternative is also not acceptable: if these phrases were generated by means of rules in the lexicon, these rules would duplicate the function of the rules responsible for generating the corresponding phrases in the syntax. 
FOOTNOTES

\begin{abstract}
*This paper is based on parts of an M.A.-thesis, which I am writing under the supervision of Prof. R.P. Botha at the University of Stellenbosch.
\end{abstract}

1. Afrikaans, a language spoken in the Republic of South Africa, is historically related to Dutch.

2. It is in accordance with this principle that Roeper and Siegel (1978: 206) propose that root compounds be inserted into the atomic core. By which principles the insertion takes place they do not explain (cf. also 83.1 below).

3. Cf. also footnote 2 .

4. Roeper and Siegel (1978:213) note that the Compound Rule could be stated as three separate rules, one for each affix. They prefer to collapse them for maximal formal economy.

5. Note that if more than one subcategorization frame is filled by the Subcategorization Insertion Rule, the Compound Rule (8) will not apply. In the structural description of the Compound Rule the variable $W$ ranges over empty subcategorizztion frames and not over lexical strings. Thus, if two or more frames are filled, the structural description for the Compound Rule is not satisfied.

6. For a detailed discussion of this point, cf. Roeper and Siegel (1978: 212).

7. It could be argued that the examples in (17) should be regarded as being formed by the adding of a verbal affix to a verbal phrase. This point will not be discussed in this paper, although it should be clear that even if such an analysis could be justified, it would still follow that certain WFRs involve phrases. 
REFERENCES

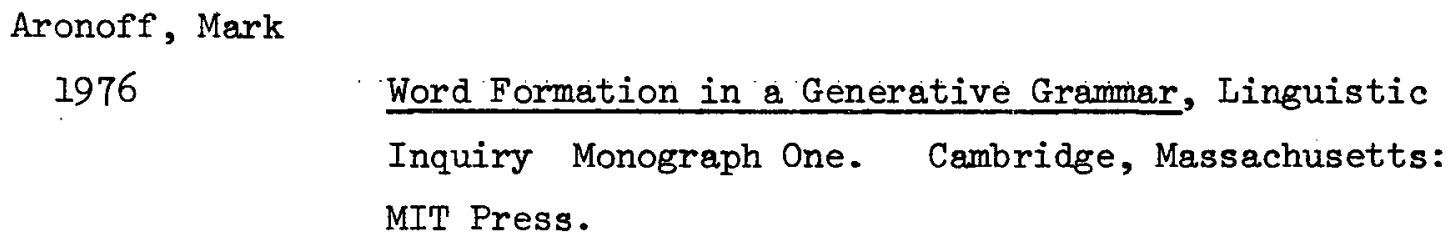

Morphological and semantic Regularities in the Lexicon. Indiana University Linguistics Club. Bloomington.

Problems in the grammatical analysis of English nominal compounds. In: M. Bierwisch and K. Heidolph (eds.), Progress in linguistics: 174-186. The Hague: Mouton. 
Roeper, Thomas and Muffy Siegel

1978

A Lexical Transformation for Verbal Compounds, Linguistic Inquiry 9 no. 2:199-260.

Siegel, Dorothy 